\title{
PROMOTIONAL ACTIVITIES AND SERVICES BANK NAGARI KAMBANG INCREASE IN CUSTOMER
}

\author{
Olivia Marta, Ratna Widayati \\ Akademi Keuangan dan Perbankan Padang \\ ratnawidayati@akbpstie.ac.id
}

\begin{abstract}
Promotion interpreted as an attempt to persuade people to accept the products, concepts, and ideas. Promotion strategy means a program of integrated control and communication methods and materials designed to bring the company and its products to prospective customers. Service is an organization / individual, a process for helping others with specific ways in order to provide the best service to the person or group of people who are served. For a discussion of research methods in the form of data types and data sources in the form of primary and secondary data, while the data collection techniques by observation, interviews, library method. The method used is descriptive method. Location of research at Bank Nagari Kambang. The object of study in this research is the promotion activities and services performed by the Bank Nagari Kambang. Promotional activities and services carried out by the Bank Nagari branch Kambang very influential in increasing the customer in every year. The purpose of this study to understand and know how promotional activities and services at branches of Bank Nagari Kambang to support this thesis required accurate data. Untuik that the collected data is secondary data and primary data.
\end{abstract}

Keywords: Activities, Promotion Services.

\section{PENDAHULUAN}

Dilihat dari kondisi perekonomian Indonesia sekarang yang semakin lesu dan memprihatinkan serta merosotnya nilai mata uang rupiah, maka dibutuhkan dana yang cukup besar untuk pembangunan perekonomian masyarakat. Oleh karena itu peranan lembaga perbankan sebagai fasilitor pembangunan sangat penting, yaitu memberikan jasa dalam membiayai usahausaha yang produktif yang pada akhirnya dapat meningkatkan pertumbuhan ekonomi.

Undang-undang Nomor 10 tahun 1998 tentang perbankan pasal 1 mengemukakan Bank adalah badan usaha yang menghimpun dana dari masyarakat dalam bentuk simpanan dan menyalurkannya kepada masyarakat dalam bentuk kredit dan atau bentuk-bentuk lainnya dalam rangka menigkatkan taraf hidup rakyat banyak.

Fungsi utama bank adalah menghimpun dana dari masyarakat yang berupa giro, tabungan, deposito, kemudian menyalurkannya kembali pada masyarakat dalam bentuk kredit atau pinjaman. Kredit merupakan sumber pendapatan yang terbesar bagi bank dibandingkan sumber pendapatan lainnya. 
Disatu sisi liberalisasi dibidang perbankan telah mendorong munculnya bank-bank baru dan cabang-cabang bank Asing di Indonesia, sehingga persaingan antar bank dalam memperebutkan pasar perbankan semakin ketat. termasuk di Kambang, sehingga mengharuskan Bank Nagari Kambang untuk mempertahankan dan meningkatkan nasabahnya.

Rumusan Masalah

Sesuai dengan judul diatas, maka masalah yang dibahas dalam tugas akhir ini dirumuskan sebagai berikut: Bagaimana aktivitas PT.Bank Nagari cabang Kambang dalam meningkatkan Nasabah.

\section{METODE PENELITIAN}

Penelitian yang dilakukan dengan membaca beberapa buku-buku ilmiah dan tulisan-tulisan yang berkaitan dengan pembahasan yang dilakukan dan peninjauan langsung objek penelitian untuk meneliti hasil data primer

\section{Metode Analisis Data}

Dalam menganalisis data, penulis menggunakan analisis data kualitatif sebagai metode penelitian yang menjelaskan secara deskriftif mengaenai upaya meningkatkan jumlah nasabah pada PT Bank Nagari cabang Kambang.

\section{LANDASAN TEORI}

\section{Pengertian Promosi}

Promosi diartikan sebagai upaya membujuk orang untuk menerima produk, konsep, dan gagasan. Strategi promosi berarti sebuah program terkendali dan terpadu dari metode komunikasi dan material yang dirancang untuk menghadirkan perusahaan dan produk-produknya kepada calon konsumen, menyampaikan cirri-ciri produk yang memuaskan kebutuhan untuk mendorong penjualan yang pada akhirnya memberi kontribusi pada kinerja laba jangka panjang.

Bauran promosi (promotional mix) terdiri atas lima unsur utama (Philip Kotler 2005: 265-315), yaitu:

a. Penggunaan Iklan (Adverstising)

Iklan merupakan sarana promosi yang digunakan oleh bank guna menginformasikan segala sesuatu produk yang dihasilkan oleh bank.

b. Promosi Penjualan (Sales Promotion)

Sales promotion merupakan promosi yang digunakan untuk meningkatkan penjualan melalui potongan harga atau hadiah pada waktu tertentu terhadap barang-barang tertentu pula. Tujuan promosi penjualan ini adalah untuk meningkatkan penjualan atau meningkatkan jumlah nasabah.

c. Publisitas / Hubungan Masyarakat (publicity)

Merupakan promosi yang dilakukan untuk meningkatkan citra bank didepan para calon nasabah atau nasabahnya melalui kegiatan sponsorship terhadap suatu kegiatan amal, sosial dan olahraga. Promosi yang ketiga ini merupakan kegiatan promosi untuk memancing nasabah melalui kegiatan seperti pameran, bakti sosial serta kegiatan lainnya.

d. Penjualan Pribadi (Personal Selling)

Merupakan promosi yang dilakukan melalui pribadi-pribadi karyawan bank dalam melayani, serta ikut mempengaruhi nasabah. 


\section{e. Direct Marketing}

Promosi jenis ini dalam penggunaan menggunakan surat, telepon, faksimil, e-mail dan alat penghubung nonpersonal lain untuk berkomunikasi secara langsung dengan mendapatkan tanggapan langsung dari nasabah tertentu dan calon nasabah.

\section{Pengertian Pelayanan}

Pelayanan menurut Kasmir diartikan sebagai kegiatan atau perbuatan seseorang atau organisasi untuk memberikan kepuasan kepada pelanggan atau nasabah. Setiap bank ingin dianggap baik oleh nasabah karena nasabah akan menjadi pelanggan setia terhadap produk atau jasa yang ditawarkan. Disamping itu bank juga berharap dari kualitas dan mutu pelayanan yang diberikan, nasabah dapat ikut mempromosikan bank kepada nasabah lain.

Pelayanan yang baik didorong oleh beberapa faktor yang berpengaruh langsung terhadap pelayanan yang diberikan. Pertama adalah, faktor manusia yang memberikan pelayanan tersebut, dan faktor kedua adalah tersedianya sarana dan prasarana yang mendukung kecepatan, ketepatan, dan keakuratan pekerjaan. Selain faktor diatas, ada pula faktor pendukung yang berpengaruh terhadap mutu pelayanan.

Berdasarkan definisi di atas dapat diambil kesimpulan bahwa pelayanan atau service adalah suatu organisasi/perorangan, suatu proses membantu kepada orang lain dengan cara-cara tertentu agar dapat memberikan layanan terbaik kepada orang atau sekelompok orang yang dilayani.

Persyaratan yang harus dipenuhi pelaku ( penyedia jasa ) agar layanan yang diberikan memuaskan kepada orang atau sekelompok orang yang dilayani, yaitu :

a. Tingkah laku yang sopan.

b. Cara menyampaikan sesuatu yang berkaitan dengan apa yang seharusnya diterima oleh orang yang bersangkutan.

c. Waktu menyampaikan yang tepat.

\section{Pengertian Bank dan Fungsi Bank}

Undang-Undang Nomor 10 Tahun 1998 (Pasal 1) tentang perubahan Undang-Undang Nomor 7 tahun 1992 tentang Perbankan menyebutkan bahwa bank adalah badan usaha yang menghimpun dana dari masyarakat dalam bentuk simpanan dan menyalurkannya kepada masyarakat dalam bentuk kredit dan atau bentuk lainnya dalam rangka meningkatkan taraf hidup rakyat banyak.

Fungsi bank yaitu sebagai penghubung (intermediary) anatara pihak yang kelebihan dana (surplus) dan pihak yang kekurangan dana (defisit) dan sebagai jasa keuangan perbankan. Dalam Undang-Undang Perbankan nomor 10 tahun 1998 (Pasal 1) tentang perubahan Undang-Undang Nomor 7 tahun 1992, terdapat beberapa perbedaan jenis perbankan yang dapat dilihat dari segi fungsi, kepemilikan dan dari segi harga.

\section{Jenis-Jenis Bank}

a. Dilihat dari segi fungsinya

1) Bank umum

Yaitu bank yang melaksanakan kegiatan usaha secara konvensional atau berdasarkan prinsip syariah yang dalam kegiatannya memberikan jasa dalam lalu lintas pembayaran 
2) Bank Perkreditan Rakyat ( BPR )

Yaitu bank yang melaksanakan kegiatan usaha secara konvensional atau berdasarkan prinsip syariah yang dalam kegiatannya memberikan jasa dalam lalu lintas pembayaran.

b. Dilihat dari segi sifatnya.

1) Bank Devisa

Merupakan bank yang dapat melaksanakan transaksi keluar negeri atau yang berhubungan dengan mata uang asing secara keseluruhan, misalnya transfer keluar negeri, inkaso keluar negeri, travellers cheque, pembukaan dan pembayaran letter of credit dan transaksi lainnya.

2) Bank Non Devisa

Merupakan bank yang belum mempunyai izin untuk melaksanakan transaksi sebagai bank devisa, sehingga tidak melaksanakan transaksi seperti halnya bank devisa, dimana transaksi yang dilakukan masih dalam batas-batas Negara.

c. Dilihat dari segi kepemilikannya.

1) Bank Milik Pemerintah

Yaitu baik akte kepemilikannya maupun modalnya dimiliki oleh pemerintah, sehingga seluruh keuntungan bank dimiliki oleh pemerintah pula.

2) Bank Milik Swasta Nasional

Yaitu bank yang seluruh atau sebagian besarnya dimiliki oleh swasta nasional serta akte pendiriannyapun didirikan oleh swasta, begitu pula keuntungan diambil oleh swasta pula.

d. Dilihat dari segi cara menentukan harga

1) Bank yang Berdasarkan Prinsip Konvensional

Menetapkan bunga sebagai harga jual, baik untuk produk simpanan seperti giro, tabungan, maupun deposito. Demikian pula harga beli untuk produk pinjaman (kredit) juga ditentukan berdasarkan tingkat suku bunga tertentu. Penentuan harga ini dikenal dengan istilah spread based.

2) Bank yang Berdasarkan Prinsip Syariah

Yaitu menerapkan aturan perjanjian berdasarkan hukum islam antara bank dengan pihak lain, baik dalam hal untuk menyimpan dana atau pembiayaan usaha atau kegiatan lainnya, yang dikenal dengan prinsip bagi hasil.

\section{ANALISIS DAN PEMBAHASAN}

\section{Promosi yang dilakukan pada Bank Nagari cabang Kambang}

a. Acara undian Sikoci dua kali setahun

Tabungan sikoci merupakan tabungan yang sedang digalakkan untuk menjadi produk utama Bank Nagari. Sikoci diluncurkan pada tanggal 10 Oktober 2001 dalam rangka memobilisasi dan serta memperkuat posisi Bank Nagari dalam penghimpunan dana.

Promosi ini dilakukan untuk menarik atau mempertahankan nasabah sikoci agar tetap menabung di Bank Nagari cabang Kambang. Acara undian sikoci ini dilakukan dua kali dalam setahun.

b. Pemasangan spanduk produk Bank Nagari 
Pemasangan spanduk produk Bank Nagari dilakukan agar masyarakat mengetahui produk apa saja yang ada pada Bank Nagari. Promosi ini bertujuan untuk menarik calon nasabah agar membeli produk yang ada pada Bank Nagari cabang Kambang.

c. Pemberian bantuan dana, disetiap acara-acara Kenagarian

Promosi dalam pemberian bantuan dana ini bertujuan untuk pendekatan kepada calon nasabah, serta mempertahankan hubungan yang baik antara bank dengan nasabah yang sudah ada pada Bank Nagari cabang Kambang.

d. Pemberian hadiah kepada nasabah yang menjadi nasabah baru berupa, jam dinding, payung, baju, gelas, dan lain-lain.

Pemberian hadiah kepada nasabah bertujuan untuk menarik nasabah baru agar tetap menabung pada Bank Nagari cabang Kambang. Hadiah yang diberikan kepada nasabah berupa jam dinding, payung, baju, dan lain-lain.

\section{Pelayanan yang dilakukan pada Bank Nagari Kambang}

Dalam operasional Bank Nagari cabang Kambang, pelayanan lebih banyak dilakukan oleh Customer Service. Adapun aktivitas yang dilakukan oleh customer service pada Bank Nagari cabang Kambang adalah:

a. Melayani nasabah yang membuka rekening simpanan tabungan, giro, deposito

Dalam hal ini Customer Service melayani nasabah dengan ramah, memberikan senyuman kepada nasabah, sabar dalam menjelaskan cara mengisi data nasabah, hingga selesai.

b. Menerima dan menindak lanjuti keluhan nasabah

Dalam pelayanan keluhan nasabah, Customer Service harus mendengarkan keluhan nasabah dengan baik dan memproses keluhan nasabah tersebut.

c. Memberikan informasi saldo dan transaksi rekening

Customer Service dalam memberikan imformasi saldo dan transaksi rekening memakai bahasa yang baik dan jelas. Sehingga mudah dimengerti oleh nasabah. Ramah, sabar, dan sopan dalam menghadapi nasabah.

d. Mencetak buku tabungan nasabah

Dalam hal ini Customer Service harus ramah, sabar, dan sopan dalam melayani nasabah yang ingin mencetak buku tabungan. Menerima dan mengembalikan buku tabungan kepada nasabah harus menggunakan tangan kanan. Karena kesopanan dalam bersikap, akan membuat nasabah merasa nyaman dan memuaskan terhadap pelayanan yang ada pada Bank Nagari cabang Kambang.

e. Memberikaninformasi yang berkaitan dengan produk/ jasa bank.

Informasi yang diberikan diantaranya menjelaskan jenis-jenis produk yang dimiliki oleh bank, syarat-syarat lain yang dimiliki, dimana informasi ini disampaikan secara langsung kepada nasabah yang ingin mengetahui atau ingin membeli produk yang disediakan pada Bank Nagari cabang Kambang. Dalam memberikan imfrormasi, Customer Service menggunakan bahasa yang baik, jelas dan mudah dimengerti. Menjelaskan kelebihan produk/jasa bank dengan sabar, tidak ragu-ragu. Agar calon nasabah ingin membeli produk tersebut.

f. Membantu nasabah untuk memastikan kelengkapan pengisian aplikasi transfer, penarikan sebelum diteruskan kepada teller. 
Customer Service harus memeriksa atau memastikan pengisian aplikasi transfer, penarikan untuk mengurangi kesalahan pada pengisian aplikasi tersebut.

\section{Tabel 1}

Perkembangan Jumlah Nasabah

Pada Bank Nagari cabang Kambang

\begin{tabular}{|c|l|l|l|l|}
\hline No & Nasabah & $\mathbf{2 0 1 3}$ & $\mathbf{2 0 1 4}$ & $\mathbf{2 0 1 5}$ \\
\hline 1 & NasabahTabungan & 11.287 & 13.716 & 14.103 \\
\hline 2 & Nasabah Giro & 16 & 18 & 23 \\
\hline 3 & Nasabah Deposito & 58 & 64 & 97 \\
\hline 4 & Nasabah ATM & 1776 & 1.868 & 2.354 \\
\hline 5 & Asset & 130.688 & 141.604 & 150.217 \\
\hline
\end{tabular}

Sumber : Bank Nagari cabang Kambang

Dari tabel diatas, bisa dilihat jumlah nasabah Bank Nagari pada tahun 2013, 2014, 2015 mengalami peningkatan. Nasabah tabungan pada tahun 2013 berjumlah 11.287 orang mengalami peningkatan di tahunb 2014 berjumlah sebanyak 13.716 orang, dan pada tahun 2015 juga mengalami peningkatan menjadi 14.103 orang. Nasabah Giro pada tahun 2013 berjumlah seabnyak 16 orang, mengalami peningkatan di tahun 2014 berjumlah sebanyak 18 orang, dan pada tahun 2015 juga mengalami peningkatan menjadi 23 orang. Nasabah Deposito pada tahun 2013 adalah sebanyak 58 orang, mengalami peningkatan di tahun 2014 berjumlah sebanyak 64 orang, dan pada tahun 2015 meningkat menjadi 97 orang. Naasabah ATM pada tahun 20131.776 orang,dan pada tahun 2014 meningkat menjadi 1.868 orang, dan pada tahun 2015 juga mengalami peningkatan menjadi 2.354 orang. Asset pada Bank Nagari cabang Kambang juga mengalami peningkatan, pada tahun 2013 asset berjumlah sebanyak 130.688, pada tahun 2014 meningkat menjadi 141.604 Milyar dan Pada tahun 2015 juga mengalami peningkatan menjadi 150.217 Milyar.

Berdasarkan data di atas, maka jumlah nasabah Bank Nagari cabang Kambang telah mengalami peningkatan setiap tahunnya. Dan peningkatan jumlah nasabah tersebut terjadi karena adanya promosi dan pelayanan yang dilakukan oleh Bank Nagari cabang Kambang.

\section{PENUTUP}

\section{Kesimpulan}

a. Aktivitas promosi yang dilakukan oleh Bank nagari cabang Kambang yang dapat meningkatkan jumlah nasabah adalah acara undian Sikoci dua kali setahun, pemasangan spanduk Bank Nagari, pemberian bantuan dana disetiap acara-acara kenagarian, pemberian hadiah kepada nasabah yang menjadi nasabah baru.

b. Peningkatan jumlah nasabah pada Bank Nagari cabang Kambang terjadi karena adanya promosi-promosi dan pelayanan yang baik.

c. Aktifitas promosi dan pelayanan yang dilakukan oleh Bank Nagari cabang Kambang sangat berpengaruh dalam peningkatan Nasabah disetiap tahunnya. 


\section{Saran}

Agar Bank Nagari cabang Kambang tetap sehat dan dapat meningkatkan serta mempertahankan nasabah, maka bank harus menjalankan kegiatankegiatan promosi, serta melakukan aktifitas pelayanan dengan baik.

\section{DAFTAR PUSTAKA}

Andika, A., \& Susanti, F. (2018). Pengaruh Marketing Mix Terhadap Keputusan Pembelian Parfum di Azzwars Parfum Lubeg Padang. https://doi.org/10.31227/osf.io/upgc3

Boyd, Walker dan Larreche. 2000. Manajemen Pemasaran : Suatu Pendekatan Strategis dengan Orientasi Global, Edisi Kedua.Jakarta : Erlangga.

Dendawijaya, Lukman. (2001). Manajemen Perbankan. Jakarta: Ghalia Indonesia.

Hasibuan, Malayu S.P. 2005. Manajemen Sumber Daya Manusia, Edisi Revisi. Bumi Aksara, Jakarta.

Hidayati, R. R., \& Marlius, D. (2018). Aktivitas Promosi Dalam Meningkatkan Dana Pihak Ketiga Pada PT. Bank Perkreditan Rakyat (BPR) Batang Kapas Pesisir Selatan. https://doi.org/10.31227/osf.io/8dgqn

Jamarnis, S., \& Susanti, F. (2019). Pegaruh Harga Dan Periklanan Melalui Internet Terhadap Keputusan Pembelian Produk Sabun Merek Lux Pada Mahasiswa STIE “KBP” Padang. https://doi.org/10.31227/osf.io/xz3d8

Kasmir, (2003) Bank dan Lembaga Keuangan Lainnya, PT. Raja Grafindo persada , Jakarta.

Kotler, Philip, (1997) Manajemen Pemasaran,Salemba Empat, Jakarta.

Latumerissa, Julius R. (2012). Bank dan Lembaga Keuangan Lain. Jakarta: Selemba Empat.

Marlius, D. (2017). Keputusan Pembelian Berdasarkan Faktor Psikologis Dan Bauran Pemasaran Pada PT. Intercom Mobilindo Padang. Jurnal Pundi. Volume 1. No. 1. Hal. 57-66. https://doi.org/10.31575/jp.v1i1.9

Marlius, D. (2016). Pengaruh Bauran Pemasaran Jasa Terhadap Minat Nasabah Dalam Menabung Pada Bank Nagari Cabang Muaralabuh. https://doi.org/10.31227/osf.io/vdqgx

Pemerintah Republik Indonesia, (2002) Undang-undang Perbankan Nomor 10 Tahun 1998 Tentang Perubahan Undang-Undang Nomor 7 Tahun 1992 Tentang Perbankan, Sinar Grafika, Jakarta. 
Safitri, R. N., \& Marlius, D. (2017). Penerapan E-Banking Dalam Meningkatkan Jasa Dan Layanan Perbankan Di PT. Bank Rakyat Indonesia Cabang Padang. https://doi.org/10.31227/osf.io/gkv8t

Sutopo dan Suryanto, Adi. 2003. Pelayanan Prima. Jakarta: Lembaga Administrasi Negara Republik Indonesia.

Susanti, F. (2015). Pengaruh Bauran Promosi Terhadap Keputusan Klien Dalam Memilih Radio Carano Sebagai Media Promosi Iklan. https://doi.org/10.31227/osf.io/b9ws7

Susanti, F. (2014). Pengaruh Tarif Iklan Terhadap Pendapatan Pada PT. Radio Swara Carano Batirai Indah Batusangkar. https://doi.org/10.31227/osf.io/dy863

Susanti, F. (2018). Faktor Faktor Yang Mempengaruhi Minat Beli Pada ECommerce Lazada.co.id (Studi Pada Mahasiswa Jurusan S1 Manajemen "STIE KBP" Padang). https://doi.org/10.31227/osf.io/um4yw

Susanti, F., \& Gunawan, A. C. (2019). Pengaruh Bauran Promosi Dan Harga Terhadap Keputusan Pembelian Produk Kosmetik Maybelline Di Kota Padang. https://doi.org/10.31227/osf.io/npjqh 